\title{
Performance Analysis and the Cost Effective Position Sensorless Control of Axial Flux PM Brushless DC Motor
}

\author{
Mohsen Ebadpour ${ }^{1}$ and Mohammad Reza Alizadeh Pahlavani ${ }^{2}$ \\ ${ }^{1}$ Young Researchers and Elite Club, Ilkhchi Branch, Islamic Azad University,m.ebadpour@yahoo.com \\ ${ }^{2}$ Department of Control Engineering, Malek-Ashtar University of Technology,mr_alizadehp@iust.ac.ir
}

\begin{abstract}
The aims of this paper are the simple comparison of the axial flux (AF) structures versus the radial flux (RF) structures for brushless permanent-magnet (PM) synchronous motors and proposing a cost effective position sensorless control strategy for AFPM Brushless DC Motor. The comparison is developed for different motor dimensions. Moreover, a cost effective and position sensorless control strategy proposed for AFPM brushless DC (BLDC) motor drive using single current sensor. It is based on the generation of quasi-square current waveforms, using only one current controller for the three phases. Unlike the conventional methods, the proposed method presents advantages such as very simple control scheme, without needing to triangular carrier modulation, and balanced phase currents. The proposed position sensorless technique is based on the detection of zero crossing points of three voltage functions that are derived from the difference between the lines'voltage measured at the terminals of the motor. This control algorithm is particularly suitable for cost sensitive product such as air purifiers, air blowers, cooling fan, and related home applications. The effectiveness of the proposed control system have been validated by simulation results.
\end{abstract}

\section{Keywords}

axial flux PM motors, radial flux PM motors, brushless DC motor, cost effective drive, electric vehicle

\section{INTRODUCTION}

Recently, axial flux permanent magnet (AFPM) motors have been the object of many researches. Different motor structures and geometries have been presented, for different applications, as an alternative to the radial flux permanent magnet (RFPM) motors [Nguyen et al., 2011; Aydin et al., 2010]. Unlike the radial flux machines, the AFPM machine category actually incorporates a large set of various possible structures, sharing in common only the two simultaneous features that give the category its name: flux running in the axial direction and having PMs on the rotor. Accordingly, the overview covers a set of different applications. Fortunately, thanks to their additional distinguishing features, it is also possible to further classify these applications and the overview follows a structure based on such a standard classification [Gieras et al., 2008].

AFPM machines are being used in various applications in recent years such as: high-speed generator driven by a gas turbine in a hybrid traction system, hybrid electric vehicle with flywheel-electrical machine combination, wheel direct drive for electric vehicles, and engine driven generator and starter motor [Ficheux et al., 2001]. Axial flux machines are differ- ent from conventional electrical machines in terms of the direction of the flux which runs parallel with the mechanical shaft of the machine. A general comparison of AFPM versus RFPM motors is not possible, due to the large number of possible technical solutions; thus, the comparison is focused on two specific types of surface-mounted PM synchronous motors: 1) the most common RFPM motors with one external stator and one internal rotor, 2) the AFPM motors with two external stators and one internal rotor. The comparison between electric motors is performed using the "sizing equations". These equations link the motor electromagnetic torque to the motor length and the diameter through coefficients depending on the electric/ magnetic material exploitation [Chen et al., 2010].

AFPM brushless DC motors are being used increasingly in numerous applications because of their high power density, compactness, high efficiency, low maintenance, and ease of control. Minimizing the cost of the motor drives is the key factor of low cost applications. Sensors and their associated accessories increase complexity, cost, and size of the motor drives and reduce the reliability of the system. Therefore, reduction of the number of sensors is desirable in motor drives. The most appealing current sampling method for BLDC motor is using only one current sensor [Ebadpour et al., 2011].

Conventional AFPM BLDC motor drives are generally implemented via a six-switch three-phase in- 
verter, three Hall Effect position sensors that generate proper signals for current commutation. However, it is a well known fact that these sensors have a great number of drawbacks; they increase the cost of the motor and require special mechanical arrangements to be mounted. Sensorless control is the reliable way to operate the motor for applications in harsh environments. Recently, several researches on sensorless control techniques of AFPM motors have been conducted. These researches can be divided into two categories: 1) Detecting the zero crossing points of the motor terminal to neutral voltage or back electromagnetic force (EMF) detection method, and 2) Using estimators or observers [Su and Mckeever, 2004].

In this paper, the presented comparison procedures are based on the motor structures and delivered electromagnetic torque. A cost effective position sensorless control for AFPM BLDC motor drives using a single current sensor is proposed. The proposed control strategy is based on just one hysteresis current controller and a PID controller for speed regulation. The main motivation of this paper is to show that replacing conventional current control methods with a simple single current control strategy without using position sensors, and reducing the cost and size of the motor drives.

\section{STRUCTURE OF THE RFPM AND THE AFPM MOTORS}

To make the comparison, several parameters are held constant or very near to each other. According to the travelling direction of magnetic flux in the air gap, PM machines are categorized into RFPM, AFPM, and transverse-flux PM (TFPM) machines. Each of them has many construction variations; depending on specific applications. But, in this paper, the comparison is limited to RFPM and AFPM brushless motors with sinusoidal or non sinusoidal back EMF and isotropic rotor structure (surface-mounted rare-earth magnet$\mathrm{NdFeB}$ ). The considered motors have slotted stators.

\subsection{RFPM Brushless Motors}

RFPM brushless DC motors or BLDC motors are being used increasingly in computers, automotive, industrial and household products because of their high power density, high efficiency, low maintenance, and ease of control. The considered RFPM structure is the common one with one external cylindrical stator and one internal cylindrical rotor. Structure of this motor has been shown in Figure 1(b). This RFPM motor is widely used in industrial applications, thus, it is considered the reference solution. The motor geometry is sketched in Figure 2(a). The dimensions are listed in Table 1 .

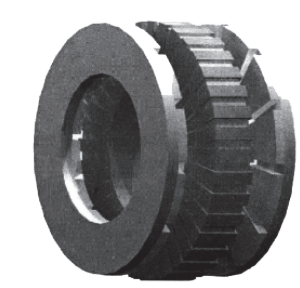

(a)

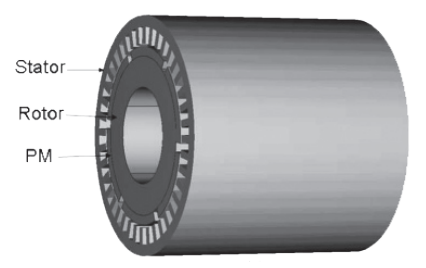

(b)

Fig. 1 Structure of two motors (a) AFPM motor, (b) RFPM motor

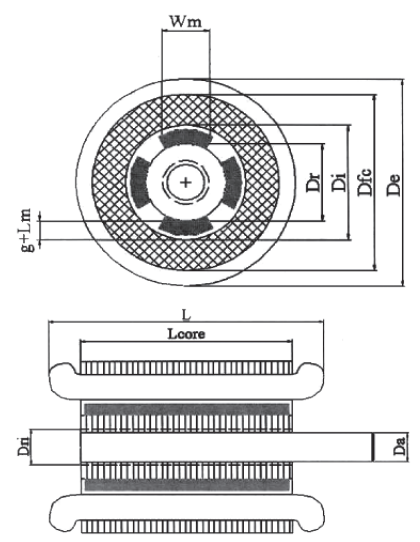

(a)

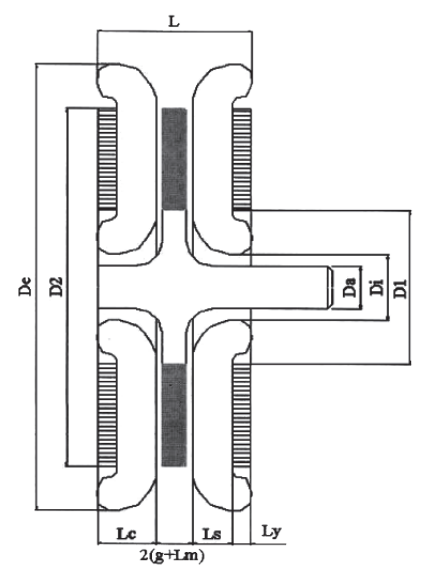

(b)

Fig. 2 Main dimensions of the a) RFPM synchronous motor, b) AFPM synchronous motor

\subsection{AFPM Brushless Motors}

AFPM machines can thus be designed to operate with square-wave or sine-wave currents. Their operation principles are quite similar, but they can be chosen for 
Table 1 Main RFPM motor dimensions

\begin{tabular}{|l|c|}
\hline Axial motor length, [m] & $L$ \\
\hline Axial stator core length, [m] & $L_{c o r e}$ \\
\hline Outer stator diameter; [m] & $D_{e}$ \\
\hline Slot bottom diameter, [m] & $D_{f e}$ \\
\hline Inner stator diameter, [m] & $D_{i}$ \\
\hline Outer rotor diameter, [m] $[\mathrm{m}]$ & $D_{r}$ \\
\hline Inner rotor diameter, $[\mathrm{m}]$ & $D_{r i}$ \\
\hline Shaft diameter, [m] & $D_{a}$ \\
\hline Magnet radial length, [m] & $L_{m}$ \\
\hline Airgap radial thickness, [m] & $g$ \\
\hline Magnet width, [m] & $w_{m}$ \\
\hline Polar pitch occupation of the, $[\mathrm{pu}]$ & $a_{m}$ \\
\hline
\end{tabular}

different types of applications. The current flowing through each stator coil interacts with the flux created by the magnets on the rotor, producing a force tangential to the rotor circumference. Among the AFPM structures, several different geometries have been proposed. In particular, the sandwiched structures with more than one stator and/or rotor seem to be the most attractive. As shown in Figure 1(a), the motor considered in this paper is realized by two external rotors and one internal double sided stator. Figure 2(b) shows the typical AFPM motor view and the main dimensions reported in Table 2.

AFPM machine types are basically different combinations of various features which can be classified as: (1) Stator-rotor arrangement including multi-disk structure, single-sided structure, double-sided structure (internal stator and internal rotor), (2) Existence of armature slots including slotted stators and toroidallywound slotless stators, (3) The technique to integrate the permanent magnet to the rotor including surface-

Table 2 Main AFPM motor dimensions

\begin{tabular}{|l|c|}
\hline Axial motor length, [m] & $L$ \\
\hline Outer motor diameter; [m] & $D_{e}$ \\
\hline $\begin{array}{l}\text { Inner end winding connection di- } \\
\text { ameter, [m] }\end{array}$ & $D_{i}$ \\
\hline Inner stator core diameter, [m] & $D_{1}$ \\
\hline Outer stator core diameter, [m] & $D_{2}$ \\
\hline Shaft diameter, [m] & $D_{a}$ \\
\hline Slot axial length, [m] & $L_{s}$ \\
\hline Stator yoke axial length, [m] & $L_{y}$ \\
\hline Stator axial length, [m] & $L_{c}$ \\
\hline Half magnet axial length, [m] & $L_{m}$ \\
\hline Airgap radial thickness, [m] & $g$ \\
\hline Polar pitch occupation of the, $[\mathrm{pu}]$ & $a_{m}$ \\
\hline
\end{tabular}

mounted PM type and internal or buried PM type. In the AFPM motors, the active height useful for the torque generation is $\left(D_{2}-D_{1}\right) / 2$. Considering the endwindings encumbrance, this height depends on the $D_{e}$ and $D_{i}$ difference.

\section{TORQUE COMPARISON}

The comparison between electric motors is often performed using the "sizing equations," which link the motor electromagnetic torque to the active motor length and to the motor reference diameter. In the case of RFPM machines, the torque equation can be derived through Lorentz force equations. For the RFPM motors, the most frequently encountered sizing equation is in the form:

$T_{e}=\varepsilon_{r} \cdot D_{r}^{2} \cdot L$

Where $D_{r}(m)$ is the air-gap diameter, and $L(m)$ is the active axial length of the stator core. The coefficient $\varepsilon_{r}\left(\mathrm{~N} . \mathrm{m} / \mathrm{m}^{3}\right)$ depends on the air-gap flux density and on the chosen electric loading. A comparison between the AFPM synchronous motors and the RFPM ones, based on (1), is reported in [Zhang et al., 1996]. Equation (1) does not take into account the actual flux and current densities that are present in the different motor parts; thus, the electric and the magnetic loads have to be chosen by the designer on the basis of experience. The problem remains unchanged also using other forms of sizing equations such as, for instance,

$T_{e}=\varepsilon_{e} \cdot D_{e}^{3} \cdot L$

Where $D_{e}(m)$ is the external motor diameter and the coefficient $\varepsilon_{e}\left(\mathrm{~N} . \mathrm{m} / \mathrm{m}^{4}\right)$ depends on the flux density in the stator yoke, in the stator tooth, and on the current density in the conductors. According to the results obtained in this study, the AFPM machine topology performs better in applications for which the RFPM machine should be designed such that the value of the length ratio (axial length of stator stack vs. air-gap diameter) is below $0.4 \cdots 0.6$.

\section{THREE-PHASE AFPM BLDC MOTOR MOD-} EL

The stator windings of AFPM motor is different from RFPM ones but we can use conventional BLDC model for AFPM BLDC motor and the difference is in stator parameters like calculation of inductances. But we don't need these parameters because we can obtain parameters by measurement. In addition there is no difference between the Back-EMF produced by a PM and that produced by an excited coil [Holmes and Lipo, 2003]. Hence the mathematical model of 
an AFPM BLDC Motor is similar to that of the radial BLDC motor. The object of study in this paper is double-sided AFPM brushless machine with internal salient-pole stator and two external rotors shown in Figure 1(a).

BLDC motor is driven by a three phase inverter with so called "six-step commutation". The conducting interval for each phase is 120 electrical degrees. Therefore, only two phases are energized in each step, leaving the third phase floating. The commutation times are governed by the rotor position that can be either detected by appropriate sensors, or estimated from motor parameters in a sensorless system [Miller, 1989]. For a three phases AFPM BLDC motor the back-EMF and phase current waveforms with $120^{\circ}$ conduction mode are shown in Figure 3.

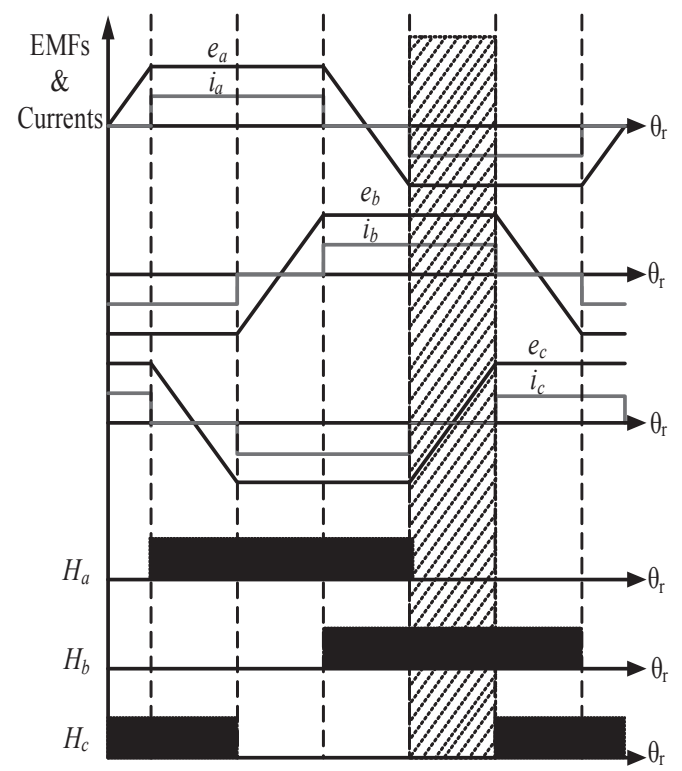

Fig. 3 Signal waveforms in the AFPM BLDC motor

The analysis of an AFPM BLDC motor is described as following equations:

$\left[\begin{array}{c}v_{a} \\ v_{b} \\ v_{c}\end{array}\right]=\left[\begin{array}{ccc}R & 0 & 0 \\ 0 & R & 0 \\ 0 & 0 & R\end{array}\right]\left[\begin{array}{c}i_{a} \\ i_{b} \\ i_{c}\end{array}\right]+\left[\begin{array}{ccc}L & 0 & 0 \\ 0 & L & 0 \\ 0 & 0 & L\end{array}\right] \frac{d}{d t}\left[\begin{array}{c}i_{a} \\ i_{b} \\ i_{c}\end{array}\right]+\left[\begin{array}{c}e_{a} \\ e_{b} \\ e_{c}\end{array}\right](3)$

$L=\left(L_{S}-L_{M}\right)$

$i_{a}+i_{b}+i_{c}=0$

where $v_{a}$ represents terminal phase $a$ voltage with respect to the power ground, $i_{a}$ is the rectangular-shaped phase $a$ current, $e_{a}$ is the trapezoidal-shaped back EMF, and $R, L_{S}$ and $L_{M}$ are resistance, self-inductance and mutual-inductance, respectively. The back-EMFs inducted in the windings are obtained from these equations:

$$
\left\{\begin{array}{l}
e_{a}=k_{E} \cdot \omega_{m} \cdot F\left(\theta_{r}\right) \\
e_{b}=k_{E} \cdot \omega_{m} \cdot F\left(\theta_{r}-\frac{2 \pi}{3}\right) \\
e_{c}=k_{E} \cdot \omega_{m} \cdot F\left(\theta_{r}+\frac{2 \pi}{3}\right)
\end{array}\right.
$$

Where $\omega_{m}$ is the mechanical speed of the rotor and $k_{E}$ is the back-EMF constant. $\theta_{r}$ is the electrical position of rotor.

The electromagnetic torque is expressed as:

$$
\begin{aligned}
T_{e m} & =D \cdot \omega_{m}+J \cdot \frac{d \omega_{m}}{d t}+T_{L} \\
& =\frac{1}{\omega_{m}}\left(e_{a} i_{a}+e_{b} i_{b}+e_{c} i_{c}\right)
\end{aligned}
$$

where $D, J$, and $T_{L}$ are friction coefficient, moment of inertia, and load torque, respectively.

\section{POSITION SENSORLESS METHOD}

Sensorless strategies have been developed to overcome technical problems raised in the conventional drive systems. Back EMF can be used to estimate rotor position and speed in high speeds. The proposed position sensorless AFPM BLDC motor drive, is based on the detection of back EMF zero crossing from the terminal voltages [Ebadpour et al., 2011]. Considering an AFPM BLDC motor with three stator phase windings connected in star. From the equation (3), difference of line voltage $v_{b c c a}=v_{b c}-v_{c a}$ may be determined as:

$$
\begin{aligned}
v_{b c c a}= & R\left(i_{b}-2 i_{c}+i_{a}\right)+L \frac{d\left(i_{b}-2 i_{c}+i_{a}\right)}{d t} \\
& +e_{b}-2 e_{c}+e_{a}
\end{aligned}
$$

Consider the interval when phases $a$ and $b$ are conducting and phase $c$ is open as indicated by the shaded region in Figure 3. In this interval, phase $b$ winding is connected to the positive polarity of the DC supply, phase $a$ to the negative polarity of the DC supply and phase $c$ is open. Therefore $i_{b}=-i_{a}$ and $i_{c}=0$. It can be seen from Figure 3 (shaded region) that the back EMF in phases $a$ and $b$ are equal and opposite. Therefore, in that interval, equation (8) may be simplified as:

$v_{b c c a}=e_{b}-2 e_{c}+e_{a}=-2 e_{c}$

Thus, the back EMF of phase c may be estimated. It is again evident from Figure 3 that during this interval (shaded region) the back EMF $e_{c}$ transients from one polarity to another zero crossing. Therefore, operation 


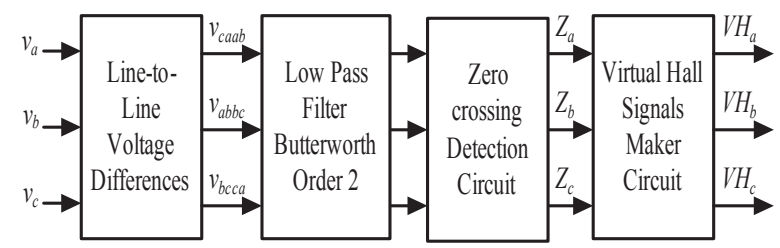

Fig. 4 Diagram of the proposed back EMF Zero Crossing Estimation Method

$v_{b c c a}$ enables the detection of zero crossing of phase $c$ back EMF. Similarly, the difference of line-to-line voltage $v_{a b b c}$ enables the detection of zero crossing of phase $b$ back EMF when phases $a$ and $c$ back EMFs are equal and opposite. The difference of line-toline voltage $v_{\text {caab }}$ waveform gives the zero crossing of phase $a$ back EMF, where phases $c$ and $b$ have equal and opposite back EMFs. Therefore, the zero crossing instants of the back EMF waveforms may be estimated indirectly from measuring only the three terminal voltages of the motor. By means of the estimated back EMFs, virtual Hall sensor signals are made as shown in Figure 4.

Figure 5 shows the simulated back EMF waveform of phase $\mathrm{c}$ and the line voltage difference. As shown in Figure 5(a), the $v_{b c c a}$ waveform contains voltage spikes appearing at the commutation instants. These voltage spikes are the result of conduction of the freewheeling diode at the phase commutation instants and

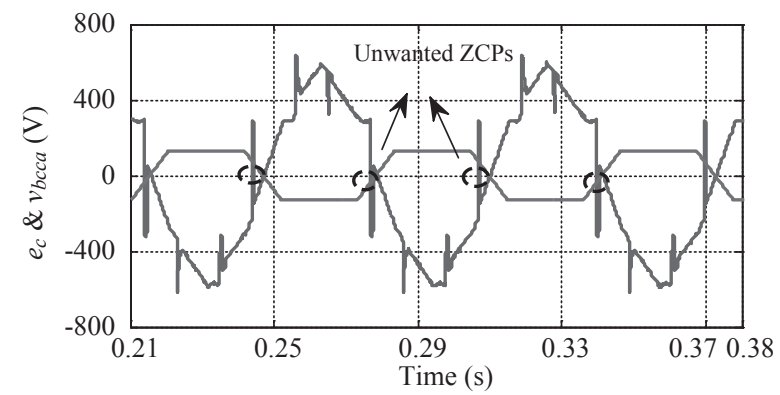

(a)

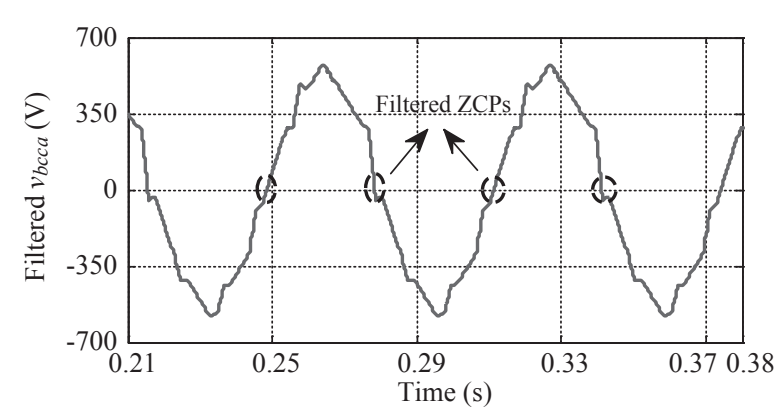

(b)

Fig. 5 Detection of back EMF zero crossing, (a) Unfiltered $v_{b c c a}$ voltage waveform and back EMF of phase $c$, (b) Filtered $v_{b c c a}$ voltage waveform are to be filtered out. Otherwise they cause unwanted zero crossing points. To eliminate this, three low pass filters typed Butterworth order 2 are chosen.

\section{CONTROL SYSTEM DESCRIPTION}

The common control algorithm for a PM motor is PWM current control. It is based on the measurement of phase current, which is compared and forced to follow a quasi-square template. Another current control method is the using a variable DC voltage source to control the applied voltage. It can have some advantages over the PWM control scheme. A linear power stage is cheaper than a pulsed power stage but the losses can be high at a low voltage and high current. However, at a high speed, a linear power stage can be the best alternative when switching losses and commutation delay of a pulsed power stage are significant [Li et al., 2008].

Block diagram of the proposed control strategy has been shown in Figure 6. For control of rotor speed, the PID controller is used to improve the dynamic response and reduce the steady-state error. Ultimately the hysteresis current controller regulates the winding currents within the small band around the DC reference current. The electromagnetic torque is directly commanded by current reference. The larger the current reference, the higher torque produced. Also restriction is expelled on the PID speed controller output depending on the permissible maximum winding currents. This expelled restriction causes a good compatibility with practical control systems.

\section{SIMULATION RESULTS}

To verify the performance of the proposed system, a number of simulations were carried out for different operating conditions, and simulation models have been established using MATLAB/SIMULINK. The sampling interval and the magnitude of the current hysteresis band are $5 \mu \mathrm{sec}, 0.2 \mathrm{~A}$, respectively. The parameters of the AFPM BLDC motor and simulation are listed in Table 3.

At first, starting and speed reversal performance of the sensorless drive were considered. For this purpose, a SIMULINK model was developed as demonstrated in Figure 6. Motor starts with nominal speed $1000 \mathrm{rpm}$ in half-load condition. At $\mathrm{t}=0.25 \mathrm{~s}$ speed reversal command is applied. Figure 7 illustrates that the motor drive tracks speed command well.

A set of further simulations was carried out to evaluate loading performances of the system. Drive system starts in half-load $(1.1$ N.m) condition and then a nominal load $(2.2 \mathrm{~N} . \mathrm{m})$ is applied to AFPM motor after $0.2 \mathrm{~s}$. Afterwards, motor is half-loaded at $\mathrm{t}=0.3 \mathrm{~s}$. Motor speed in these conditions is fixed and equal 100 


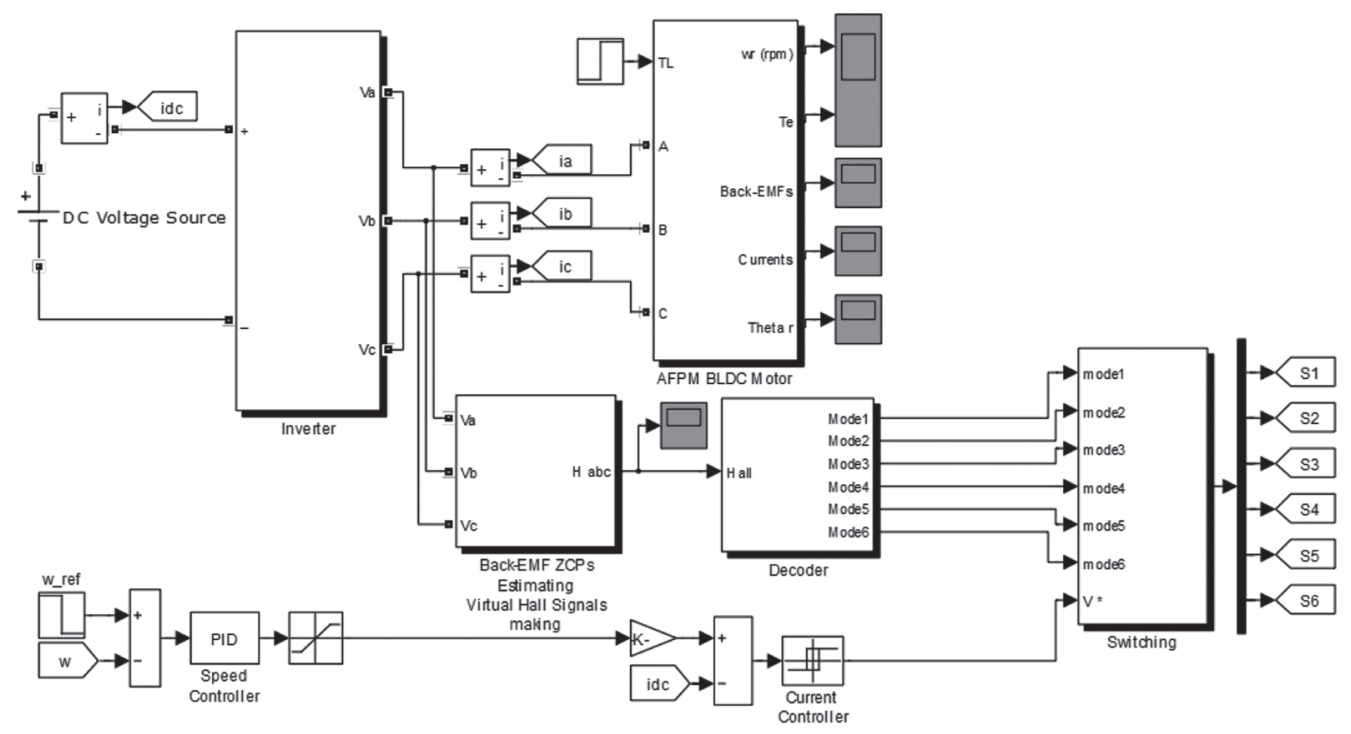

Fig. 6 Block diagram of proposed AFPM BLDC motor drive

Table 3 Simulation Parameters of the AFPM BLDC Motor Drive

\begin{tabular}{|l|c|}
\hline Parameters & Value \\
\hline Phase resistance & $8 \Omega$ \\
\hline Phase inductance & $42 \mathrm{mH}$ \\
\hline Rated speed & $1000 \mathrm{rpm}$ \\
\hline dc-link voltage & $300 \mathrm{~V}$ \\
\hline Pole pairs & 2 \\
\hline Rated torque & $2.2 \mathrm{~N} . \mathrm{m}$ \\
\hline Inertia & $0.001\left(\mathrm{~kg} \cdot \mathrm{m}^{2}\right)$ \\
\hline Friction factor & $0.001(\mathrm{~N} . \mathrm{m} . \mathrm{s})$ \\
\hline Back-EMF constant & $1.324 \mathrm{~V} /(\mathrm{rad} / \mathrm{sec})$ \\
\hline
\end{tabular}

$\mathrm{rad} / \mathrm{sec}$. The obtained results have been illustrated in Figure 8, and shows that the speed performance of the AFPM BLDC motor is well. The simulation results clearly indicate that the electromagnetic torque gives good performances under loading conditions and has very low ripple. The line to line voltage of motor has been shown in Figure 9.

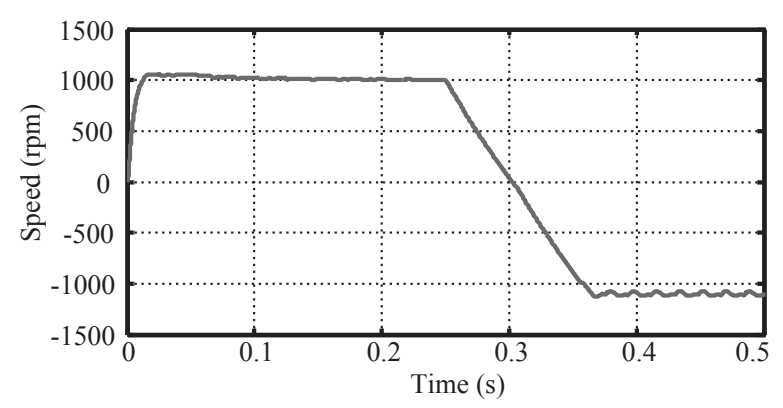

Fig. 7 Rotor speed at positive and negative rate

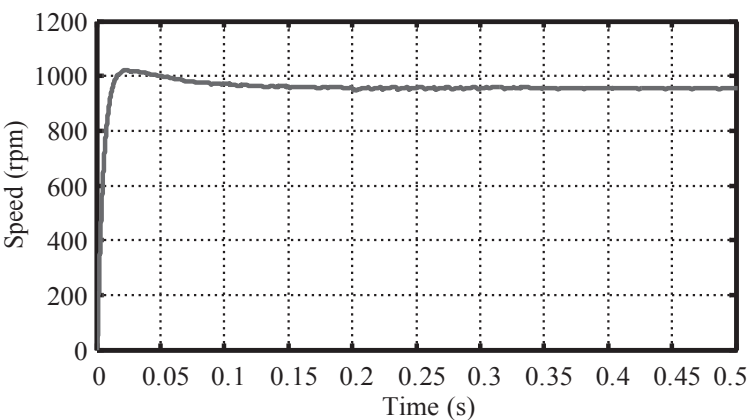

(a)

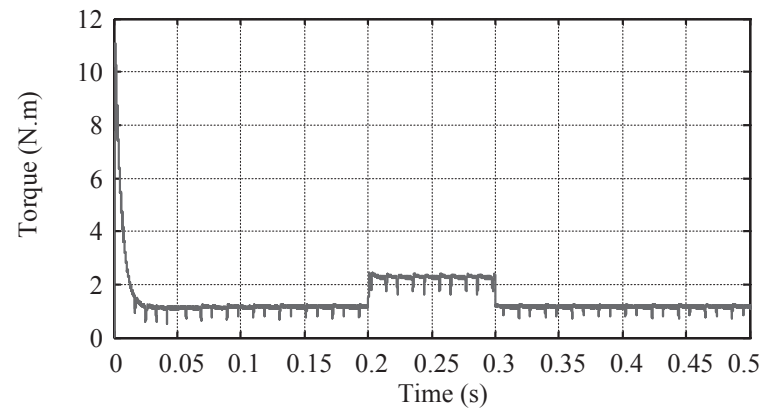

(b)

Fig. 8 Motor performance under loading condition (a) motor Speed, (b) electromagnetic torque

\section{CONCLUSION}

In this paper, a method was provided to compare the two rather different PM synchronous motors structures: the two rotor one double-sided stator AFPM BLDC motors and the conventional RFPM motors. The two motor structures were compared in terms of provided electromagnetic torque and torque density, when the overall motor volume, the losses per wasting surface, and the air-gap flux density are kept constant. 


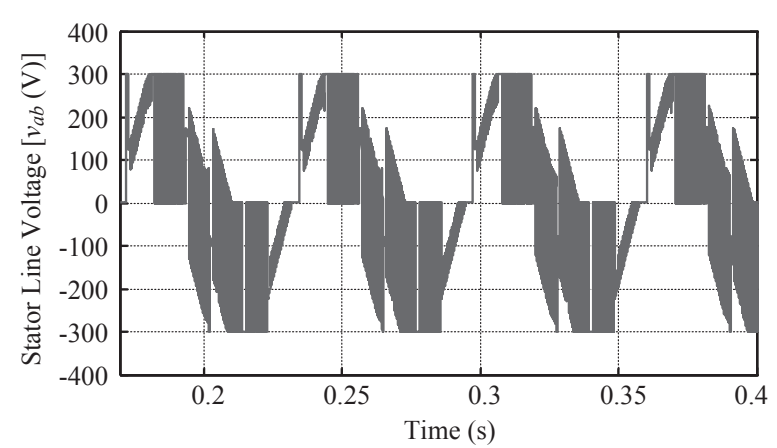

Fig. 9 Line to line voltage of motor

Moreover, a cost effective, higher performance AFPM BLDC motor drive system has been proposed. To sample the phase current at any instant, an effective single current sensor technique without the need for information of freewheeling current or current sign has been adopted. Virtual Hall sensor signals are made by detection of zero crossing points of the difference of line voltage measured at the terminals of the motor. In the proposed sensorless scheme, no phase shift is required, which is prevalent in most of sensorless algorithms. Compared to the conventional BLDC motor drive scheme, it is not complicated and eliminates the use of complex hardware.

\section{Acknowledgements}

The Corresponding author would like to thank the "Young Researchers and Elite Club, Ilkhchi Branch, Islamic Azad University, Ilkhchi, Iran" for their kind supporting of this paper and assistance in the preparation of this research.

\section{References}

Aydin, M., S. Huang, and T. A. Lipo, Design, analysis, and control of a hybrid field-controlled axial-flux permanent-magnet motor, IEEE Transactions on Industrial Electronics, Vol. 57, No. 1, 78-87, 2010.

Chen, A., R. Nilssen, and A. Nysveen, Performance comparisons among radial-flux, multistage axialflux, and three-phase transverse-flux PM machines for downhole applications, IEEE Transactions on Industrial Applications, Vol. 46, No. 2, 779-789, 2010.

Ebadpour, M., M. B. B. Sharifian, and M. R. Feyzi, A cost-effective position sensorless control for fourswitch three-phase brushless DC motor drives using single current sensor, International Review of Automatic Control, Vol. 4, No. 3, 386-393, 2011.

Ficheux, R. L., F. Caricchi, F. Crescimbini, and O. Honorati, Axial-flux permanent-magnet motor for direct-drive elevator systems without machine room, IEEE Transactions on Industrial Applica- tions, Vol. 37, No. 6, 1693-1701, 2001.

Gieras, J. F., R-J. Wang, and M. J. Kamper, Axial Flux Permanent Magnet Brushless Machines, Kluwer Academic Publishers, 2008.

Holmes, D. G., and T. A. Lipo, Pulse Width Modulation for Power Converters-Principle and Practice, IEEE Press/Wiley-Interscience, 2003.

Li, Q., H. Huang, and B. Yin, The study of PWM methods in permanent magnet brushless DC motor speed control system, International Conference on Electrical Machines and Systems ICEMS, 38973900, 2008.

Miller, I., Brushless Permanent-magnet and Reluctance Motor Drives, Clarendon Press, 1989.

Nguyen, T. D., K-J. Tseng, S. Zhang, and H. T. Nguyen, A novel axial flux permanent-magnet machine for flywheel energy storage system: Design and analysis, IEEE Transactions on Industrial Electronics, Vol. 58, No. 9, 3784-3794, 2011.

$\mathrm{Su}, \mathrm{G}$. J., and W. Mckeever, Low-cost sensorless control of brushless DC motors with improved speed range, IEEE Transactions on Industrial Electronics, Vol. 19, No. 2, 296-302, 2004.

Zhang, Z., F. Profumo, A. Tenconi, Axial flux versus radial flux PM machines, Electromotion, Vol. 3, No. 3, 23-29, 1996.

(Received October 24, 2013; accepted November 19, 2013) 